\title{
Studies in the Physiology of Parasitism.
}

\section{On the Exosmosis of Nutrient Substances from the Host Tissue into the Infection Drop.}

BY

\author{
WILLIAM BROWN, M.A., D.Sc.
} (From the Department of Plant Physiology and Pathology, Imperial College of Science and
Technology, London.)

With one Figure in the Text.

$\mathrm{I}^{\mathrm{N}}$ previous papers of this series ${ }^{1}$ it was shown that the fungus Botrytis I cinerea, though possessing an active cytolytic principle, was unable to act upon the cells of the host tissue so long as an intact cuticle separated it from them. Evidence was brought forward to show that the penetration of the cuticular membrane was effected by mechanical rupture, and it was only when this had taken place that the fungus was able to attack directly the host cells. So far the question had been treated from the point of view of the influence of the parasite upon the host. There still remained for examination the converse relation of host to parasite. For whereas, antecedent to penetration, the tissue of the host was found to be wholly unaffected by the presence of the parasite, it appeared not improbable that the host plant might be able to influence in some way the behaviour of the parasite. Such an influence might take the form of a stimulus to germination or of a chemotropic stimulus. The present paper deals with the former question, viz. with the passive exosmosis of nutrient material from the host cells through the cuticle.

The method of experiment generally was as follows: Drops of distilled water of a standard size (c. 0.05 c.c.) were laid on the surface of plant organs and allowed to remain for some time, generally for twenty-four hours. They were then removed and examined to see whether any change had taken place in them due to their having been in contact with the plant.

Two methods of examination were adopted :

(I) Determination of the electrical conductivity of the fluid.

(2) Determination of the effect of the fluid on the germination of fungal spores.

1 Ann. Bot., vol. xxx, 1916, pp. 389, 399.

[Annals of Botany, Vol. XXXVI. No. CXLI. January, 1922.] 
For the determination of conductivities, the method described by Blackman and Paine ${ }^{1}$ was employed. The cell consisted of a fine pipette with small bulb blown near the pointed end, into which the platinum leads were fused. The bulb was of such a size that it was completely filled by the drop. By means of a rubber cap with screw adjustment on the distal end of the pipette, the position of the drops in the cell could be accurately controlled. The use of a constant temperature bath was dispensed with and the readings made at laboratory temperature. In all cases the temperature was noted so that correction of results could be effected. In view of the magnitude of the differences observed, the error due to slight variations in temperature could be ignored.

To determine the capacity of the drops to stimulate spore germination, they were placed on clean glass slides, and a drop of a suspension of spores in water was added to each. Drops of water which had lain for twenty-four hours on glass slides or which came directly from the stock of distilled water were similarly treated and served as controls. After a certain time the state of the drops as regards germination of the spores was determined. In this connexion a mere count of the percentage of germinated spores is of doubtful value, as it fails to distinguish between a case where a certain percentage of spores germinates feebly and one in which a similar percentage germinates vigorously. The figure obtained in this way may thus give no true representation of the germinative picture displayed. A more accurate method was found in the measurement, by means of a micrometer eye-piece, of the total length of germ-tube of a number of spores chosen at random. In this way the 'average germ-tube length' could be determined. In view of the amount of variation which obtains between individual spores, a large number of counts and measurements $(25,50$, or I00, according to circumstances) was made in each case. This method is also incomplete, inasmuch as it fails to represent the difference between the thin feeble germ-tubes which are formed in water or very dilute nutrient and the stout vigorous ones formed in more concentrated nutrients, but it seemed to be the best available.

In general, each drop was examined according to both methods-that is, it was removed from the plant surface by means of the pipette and its conductivity determined. It was then placed on a glass slide, the suspension of spores added, and the amount of germination ensuing in a given time measured. In this way a duplicate series of results was obtained. The electrical method gives only a measure of the amount of dissociated electrolytes which have diffused out of the plant; for the purpose of determining the amount of nutrient material appearing in the drops, the spore-germination method obviously is the direct one. The degree of parallelism exhibited by the two series of results will be illustrated subsequently. 


\section{Brown.-Studies in the Physiology of Parasitism. VIII. 103}

The plant material consisted of leaves and floral structures, viz. : petals of Cereus, Phyllocactus, Gloxinia, Lilium, Tulip, Rose, Begonia, Viola, Sweet-pea, Dahlia, Geranium, Cydonia, Pyrus, and leaves of Broad Bean. A large amount of the work was carried out with the petals of Cereus spectabilis, which offers special advantages. These petals are highly and uniformly coloured, and lend themselves readily to plasmolysis studies by means of the microscope; from the same flower a large number of petals can be obtained which show similar behaviour, and which, especially when taken from the unopened bud, show a perfectly clean surface; the results obtained by both methods of experimentation are well defined ; and lastly, the petals present a flat surface and are moderately easily wetted. The latter is an important practical point which may be illustrated by a few examples. In the case of such petals as those of Viola and of some varieties of Rose, the drops do not wet the petals at all. They maintain a more or less spherical shape, and from their appearance it is clear that a film of air is entrapped between them and the surface of the petal. The drop, therefore, has only very limited contact with the petal. In such cases it is found that the exosmosis figures are always very low. Such petals are further very troublesome in use, in that the drops are very liable to shift, coalesce, or run off. At the other extreme is the case of the Bean leaf, where the drops tend to spread too far, especially along the line of the veins, thus making it impossible to ensure that the drops occupy approximately uniform areas of the plant surface. In the case of Cereus petals an intermediate degree of wetting is shown; comparatively good contact obtains between drop and petal, and the drops present a fairly uniform appearance when laid on the petals.

An attempt was made to get over this difficulty of non-wetting in the case of some plants by the addition of traces of substances such as Castile soap and saponin to the water, but the preparations tried were found to possess too high a conductivity for use in this connexion.

For the reasons given above petals of Cereus were selected for detailed examination. As was anticipated, a considerable degree of variation was obtained from drop to drop. Certain well-marked rules were, however, made out, of which the following is an account.

On the same petal the conductivity of the drops varies from place to place, being smallest in the centre along the line of the midrib, and increasing towards the distal (free) end of the petal. The greatest values are obtained along the margins, and especially near the tip. The following figures, representing the conductivity of drops which have lain in contact with the petals for twenty-four hours in a moist Petri dish at laboratory temperature $\left(17-20^{\circ} \mathrm{C}\right.$.), illustrate this point. The numbers in the diagram (see next page) indicate the position of the drops on the petal. 
(Conductivity of $\mathrm{m} / 100 \mathrm{KCl}$ at $20^{\circ}=72 \cdot 7 .^{1}$ Conductivity of the distilled water varied within the limits $0.8-\mathrm{I} \cdot 2$.

$\begin{array}{ccc} & \text { Petal I. } & \text { Petal II. } \\ \text { Drop. } & \text { Conductivity. } & \text { Conductivity. } \\ 1 & 2 \cdot 2 & 4 \cdot 0 \\ 2 & 2 \cdot 2 & 5 \cdot 4 \\ 3 & 2 \cdot 4 & 5 \cdot 1 \\ 4 & 5 \cdot 8 & 7 \cdot 4 \\ 5 & 7 \cdot 6 & 10 \cdot 3 \\ 6 & 8.5 & \text { I9.I }\end{array}$

In addition to observing that this rule held throughout all the work with Cereus, it was found in two experiments specially set up to determine this point that the average conductivity of 58 central drops was $4 \cdot 7$ (min. $2 \cdot 2$, max. I I.2), and that of 29 marginal drops was I $5 \cdot 2$ (min. 6.0, $\max .39 \cdot 4)$.

The amount of exosmosis from the same petal in a given time increases day by day. This was shown by adding new drops to the same places each day after the drops of the preceding day had been removed and examined. In such an experiment as this an appreciable risk of contamination of the drops by fungal spores is incurred, and a certain number of the petals after some days showed discoloured spots which were found to be caused by spores of Botrytis. Such petals were discarded. The following figures give the average conductivity (av. of 19 drops) obtained on three consecutive days from petals of Cereus which showed no evidence of fungal contamination on the fourth day.

$\begin{array}{lccc} & \text { Ist day. } & \text { 2nd day. } & \text { 3rd day. } \\ \text { Average conductivity. } & 3.6 & 7.8 & 18.6\end{array}$

The same type of result was obtained with petals and sepals of Tulip. In this case the rise of rate of exosmosis with time was found to be more gradual.

The effect just described is due partly to ageing of the plant structure and partly to the fact that the method of treatment results in better wetting of the petals as time goes on. Experiments in which one batch of petals was subjected to the above day-by-day treatment, while a control batch was kept for the same time without the treatment, showed that the latter gave considerably higher figures than had been given at the commencement of the experiment, but not so high as those which were being given by the 
Brown.-Studies in the Physiology of Parasitism. VIII. 105

treated petals. There is thus a distinct ageing effect (as was to be expected). The wetting effect is readily observable. It was seen that the earlier drops laid on a given spot were, on application of the pipette, readily sucked up in their entirety, whereas in the case of the later drops a film of liquid was left on the surface of the petal. Whenever surch a degree of wetting was reached, i. e. such that it was impossible to pick up the complete drop with the pipette, high exosmosis figures were invariably obtained.

The presence of pollen-grains in the drops gives rise to high conductivity figures. This is shown by the following expiment with Cereus petals. The petals were washed (without rubbing) in a stream of water, rinsed with distilled water, then allowed to dry, after which drops of distilled water were placed on each. To a certain number of these a quantity of Cereus pollen was added on the point of a platinum wire. After twenty-four hours the conductivity of the drops was measured, with the following results :-

\begin{tabular}{|c|c|}
\hline Pollen-free drops. & $\begin{array}{c}\text { Average conductivity after } 24 \text { hours (I I drops) }=3 \cdot 3 \\
\text { (min. } 2 \cdot 8, \max .4 \cdot 2)\end{array}$ \\
\hline Pollen-containing drops. & $\begin{array}{c}\text { Average conductivity after } 24 \text { hours }(6 \text { drops })=73 \cdot 8 \\
\left(\text { min. } 54 \cdot 6, \max \cdot 9^{2} \cdot 3\right)\end{array}$ \\
\hline
\end{tabular}

It should be stated that the pollen-containing drops show a greater tendency to spread over the surface of the petal than the pollen-free ones. This in itself, as giving rise to a greater area of contact with the petal, would tend to cause the conductivity figures to be higher in the former case. The disparity in this respect, however, would account for only a very small portion of the difference in conductivity observed. Similar results were obtained with pollen of Rose and Lily, and it is highly probable that they apply to pollen generally.

In determining the amount of exosmosis from the petal itself it is therefore necessary to remove completely any pollen that may be present. This can be effectively done in the manner described above.

Incidental to this necessity for the removal of pollen, it was found that mechanical rubbing, even though gentle, considerably increased the conductivity figures obtained. Thus in one experiment with petals of Cereus the average conductivity of drops laid along the midrib of washed and slightly rubbed petals was $\mathrm{J} 2.8$, whereas that of drops laid on a similar series of petals (alternating in the flower with the preceding) which had simply been rinsed amounted to only 5.0 (I 9 drops in each case). In the case of the rubbed petals it was observable that better contact between the petal and the drop had been established. The effect is undoubtedly due to the removal of the surface bloom of the petals by the mechanical treatment.

Throughout this work strict attention was paid to the question as to whether the experimental petals remained alive during the treatment. In petals generally, and in Cereus in particular, death is shown macroscopically 
by the petal becoming limp and flaccid and by the discharge of the colour. Microscopically it is shown by the failure of the cells to undergo plasmolysis in hypertonic solutions. In no case were results taken from petals which showed any discolorations due either to the accidental presence of fungal contamination or to the general ageing of the petals. Numerous tests were made on the petals at the end of each experiment to see if any diminished capacity for plasmolysis could be demonstrated. In this way it was shown that petals which had been under treatment for several days still possessed, as far as could be seen, a capacity of undergoing plasmolysis equal to that of fresh ones. In both cases, after immersion of the petals in molar potassium nitrate, a very large percentage of distinctly plasmolysed cells, i. e. with sharply marked contracted highly coloured vacuoles, is seen, together with a small percentage in which the evidence of plasmolysis is not so distinct. Numerous tests led to the conclusion that the treated and the fresh petals were indistinguishable in their plasmolytic features. It was frequently found that the experimental petals showed after several days' treatment a characteristic mottling due to the presence of numerous small translucent patches. Examination of the latter showed that they were due to injection of the intercellular spaces with liquid. The distribution of these injected patches showed no relation to the position that had been occupied by water-drops, whence it follows that the liquid was derived from the cells themselves. Such self-injected petals invariably gave high conductivity figures. Nevertheless, on immersion in molar potassium nitrate they showed a degree of plasmolysis indistinguishable from that of fresh petals.

\section{Germination Studies.}

The conductivity method was largely used on account of its ease and simplicity, but, as was pointed out above, the real criterion of the importance of exosmosis in the physiological processes of infection is the effect of the fluid of the experimental drops on fungal germination. Germination studies, carried out as already described, showed that a high conductivity figure was associated with high germinative capacity and vice versa. The degree of correspondence observed will be seen in the following table, which embodies the results obtained in an experiment specially set up for this purpose.

In this experiment petals were obtained from an unopened bud of Cereus. They were thus free from fungal contamination or other blemish. In order to obtain a wide range of conductivity figures, the water drops were allowed to remain in contact with the petals for different lengths of time. 
Brozen.-Studies in the Physiology of Parasitism. VIII. 107

\begin{tabular}{|c|c|c|c|c|c|c|}
\hline \multirow{2}{*}{\multicolumn{2}{|c|}{ Drop. }} & \multirow[t]{2}{*}{ Conductivity. } & \multicolumn{4}{|c|}{$\begin{array}{c}\text { Average length of germ-tube (in } \\
\text { micrometer divisions -av. of } 25 \\
\text { measurements). }\end{array}$} \\
\hline & & & I 2 hrs. & I 6 hrs. & $24 \mathrm{hrs}$. & $3^{6} \mathrm{hrs}$. \\
\hline \multicolumn{2}{|c|}{ Distilled water } & 0.8 & 0.16 & 0.22 & 0.20 & $.0 .4^{6}$ \\
\hline \multirow{2}{*}{\multicolumn{2}{|c|}{$\begin{array}{l}\text { Tap-water } \\
\text { Drops on Cereus petal }\end{array}$}} & $4^{8.0}$ & 0.00 & 0.00 & & \\
\hline & & I. 7 & 0.22 & 0.24 & $0.5^{8}$ & 0.80 \\
\hline ", & " & $3 \cdot 5$ & 0.60 & $I \cdot 4^{6}$ & $2 \cdot 32$ & \\
\hline$"$ & ," & $4 \cdot 5$ & 1.00 & - & $3 \cdot 3^{2}$ & $3 \cdot 4^{8}$ \\
\hline ", & ", & 4.8 & 0.76 & i. 66 & 2.60 & $2 \cdot 9^{2}$ \\
\hline ", & ," & 4.9 & c. 70 & - & $2 \cdot 44$ & 2.80 \\
\hline , & , & $8 \cdot 4$ & $2 \cdot 16$ & 3.00 & 5.00 & - \\
\hline ", & ", & 8.6 & 1.50 & 2.84 & 4.28 & - \\
\hline ," & ", & $9 \cdot+$ & 2.02 & - & $4 \cdot 28$ & $5 \cdot 16$ \\
\hline ", & " & $9 \cdot 5$ & 2.04 & $2 \cdot 7^{2}$ & 3.88 & $5 \cdot 12$ \\
\hline ," & ," & $11 \cdot 3$ & 1.84 & 2.64 & 3.92 & $6 \cdot 12$ \\
\hline ", & ," & $14 \cdot 2$ & 2.24 & - & 5.88 & 8.6 \\
\hline , & ," & 22.7 & $2.9^{2}$ & - & 6.8 & $10-20$ \\
\hline$"$ & ", & $26 \cdot \mathrm{I}$ & $2 \cdot 4^{8}$ & $5 \cdot \mathrm{I} 2$ & c. 10 & $10-20$ \\
\hline , & $"$ & $27: 4$ & $2 \cdot 5^{2}$ & 5.04 & c. IO & $10-20$ \\
\hline ", & ", & 32.0 & 3.00 & - & c. IO & $10-20$ \\
\hline & ", & $3^{2 \cdot 1}$ & $2 \cdot 7^{2}$ & - & - & $10-20$ \\
\hline ", & ," & 59.5 & 2.88 & 5.60 & c. $\mathrm{IO}$ & $10-20$ \\
\hline
\end{tabular}

The conductivity figures are arranged in ascending series. It will be seen that the germination figures increase in the same direction, though with small irregularities. When one remembers the variation in germinative capacity among spores and the necessity of carrying out the measurements of germ-tube length rapidly, and therefore over a comparatively small number of spores (in this case 25), these irregularities are not surprising.

In the following table the conductivity figures are grouped within certain limits and the corresponding amounts of germination averaged. In this table it will be seen that the irregularities have almost completely disappeared.

\section{Drop.}

Conductivity.

Distillec. water

Drops on Cereus petal

$\begin{array}{ll}\text {,, } & , \\ \text {, } & , \\ \text {,, } & \text {, } \\ \text {, } & ,\end{array}$

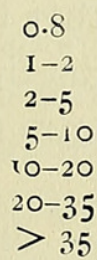

Average length of germ tube.

$\begin{array}{cccc}\text { I } 2 \text { hrs. } & 16 \text { hrs. } & 24 \text { hrs. } & 36 \mathrm{hrs} . \\ 0.16 & 0.22 & 0.20 & 0.46 \\ 0.22 & 0.24 & 0.58 & 0.80 \\ 0.76 & 1.56 & 2.67 & 3.07 \\ 1.93 & 2.85 & 4.36 & 5.14 \\ 2.04 & 2.64 & 4.90 & 7.36 \\ 2.73 & 5.08 & \text { c. I0 } & 10-20 \\ 2.88 & 5.60 & \text { c. I0 } & 10-20\end{array}$

In a similar experiment the drops which had lain on Cereus petals were compared as regards both conductivity and germinative capacity side by side with dilutions of a turnip extract. The figures are contained in the following table : 
Drop.

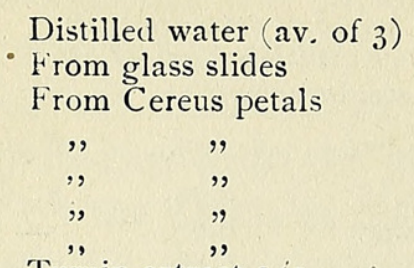

Turnip extract $\mathbf{I}$ / I

,, $1 / 5$

, ,,$\quad$ I $/ 25$

,,$\quad \mathrm{I} / \mathrm{I} 00$

,, $\quad$ I $/ 400$

, $\quad,, \quad \mathbf{I} / \mathbf{I}, 000$

, , , $\quad 1 / 4,000$

, , , I 20,000

, , , I/100,000
Conductivity.

0.70
$I \cdot I 9$
$I-2$ av. I.50
$2-3$ av. $2 \cdot 15$
$3-4$ av. $3 \cdot 7$ I
$4-5$ av. $4 \cdot 28$
$5-6$ av. 5.60
73.0
61.6
$38 \cdot 8$
16.8
6.22
3.28
$1 \cdot 40$
$1 \cdot 14$
0.77

Average length of germ tube. Io hrs. 20 hrs. $\quad 40 \mathrm{hrs}$.

$\begin{array}{lll}0.44 & 0.73 & 1.02 \\ 0.44 & 0.83 & 1.02\end{array}$

$\begin{array}{lll}0.64 & \mathrm{I} .24 & 2.20\end{array}$

$\begin{array}{lll}0.67 & \mathrm{I} .74 & 2.7 \mathrm{I}\end{array}$

I.22 $3.23 \quad 5.28$

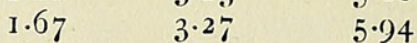

$\begin{array}{llc}2.04 & 6.08 & 7.5^{2} \\ 0.64 & 6.08 & \text { weft }\end{array}$

$2.88>10$,

$4.20>10 \quad$,

$4.28>10$,

$3 \cdot 76>10$,

$\begin{array}{lll}3.96 & 7.4^{8} & \text {, }\end{array}$

$\begin{array}{lll}3 \cdot 76 & \text { lost } & - \\ 2.80 & 4.28 & 5.48\end{array}$

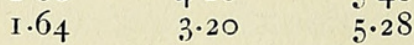

1 The compactness of the wefts was seen to be in order diminishing with dilution. The amount of growth was obviously greatest in the full strength extract.

It will be noted that the amount of germination on drops from Cereus petals is considerably less than that in turnip extract of the same conductivity. Similar dilutions of apple extract showed the same feature. This is no doubt to be ascribed to the fact that the turnip and apple extracts contain the bulk of the soluble cell contents, both those which are readily and those which are more slowly diffusible; whereas the drops from Cereus petals contain a preponderating proportion of the more readily diffusible constituents such as salts. The presence of these would raise the conductivity of the drops, while the smaller proportion present of the more slowly diffusible carbohydrates, \&c., would have the effect of making the fungal germination meagre.

Incidentally it may be seen that, as the concentration of turnip extract increases, the amount of germination passes through a maximum. This is well shown in the figures for the germination after Io hours. It is still shown to some extent after 20 hours, but has disappeared in 40 hours, when the amount of growth is greatest in the strongest extract. This feature is shown by other extracts and by other fungi than Botrytis.

The correspondence between the conductivity and the germinative capacity of the drops from Cereus petals is again clearly shown in the above table.

It will be noticed that the conductivity of drops laid on glass slides is greater than that of the original distilled water freshly taken from the stock bottle. A similar small increase in conductivity was also shown by drops laid on clean quartz slides and on glass slides maintained in a vacuum. The cause of this slight gain in conductivity was not clearly made out. It is probably due to a variety of causes, partly to solution of carbon dioxide from the air, partly to leaching of salts from the glass, and partly to accidental contamination with specks of dust. From the point of view of 
Brown.-Studies in the Physiology of Parasitism. VIII. 109

the investigation it is of no importance, as the slight gain in conductivity is not accompanied by any increase in the capacity to stimulate germination.

The failure of Botrytis spores to germinate in the tap-water (hard) is worthy of note.

The correspondence between conductivity and amount of germination was shown also for drops laid on petals of Poppy, Iris, Petunia, Geranium, and Rose.

\section{EXOSMOSIS FROM OTHER PLANTS.}

The results as detailed in the case of Cereus are paralleled in the case of other plants. A brief summary of the type of results obtained may be given here.

Petals of Phyllocactus gave figures for conductivity and germinative capacity of about the same magnitude as those of Cereus. They are, however, much inferior to the latter from the point of view of infection studies.

Petals of Tulip (var. 'Keizer Kroon'), Cydonia, Sweet-pea, Petunia, and Geranium give in general smaller conductivity figures. The effect on germination is, however, quite distinct.

Petals of Rose, Viola, Lilium, Begonia, Gloxinia, and Tulip (var. 'Darwin') give low conductivity figures and only very slight effect on germination.

The last-mentioned petals have the common feature of being difficult to wet. This is specially marked in petals of Viola, where the drops maintain an almost spherical shape and can hardly be said to be in contact with the petals at all. In the case of Begonia (female flower) it was noticed that drops on the petals showed very incomplete wetting with low conductivity and low germination figures, whereas on the ovary wings much better wetting took place, with a corresponding increase in the figures obtained for conductivity and germination. The same applied to the lobes of Gloxinia petals as compared with parts of the corolla lower down. It is highly probable that if a suitable method could be found for overcoming this difficulty of non-wetting it would be found that the amount of exosmosis and the corresponding capacity of the drops to stimulate spore germination would in all cases be considerably increased.

\section{Exosmosis in Relation to AtTACK.}

Some experiments will now be described in which the fact of exosmosis of nutrient into the infection drop is brought out by an examination of the progress of attack. This method is based on a comparison of the time required to effect attack when the spores are sown in water with that in the case in which the spores are sown in nutrient extract. 
The effect of the addition of extraneous nutrient to the infection drop is to accelerate the incidence of attack (e.g. attack of Botrytis on petals of Rose, \&c.), or in extreme cases to bring about attack where no attack takes place in its absence (e. g. attack of Botrytis on leaves of Broad Bean). In the case of a plant which allows a considerable amount of nutrient to diffuse into the infection drop, one would anticipate that the time required for spores sown in water to produce infection would approximate to that required for spores sown in nutrient extract, whereas the difference in time would be more marked in the case where less nutrient was allowed to pass out.

An experimental difficulty is met with in the fact that Botrytis spores of a certain type are able to germinate to some extent in pure water, and it is highly probable that this degree of germination is sufficient to enable them to attack delicate structures such as petals even without the addition of any nutrient to the infection drop. In order to make the results more sharply marked, measures were therefore taken to suppress the germination of the spores in pure water.

The first method depends on the fact that the germinative capacity of Botrytis spores is reduced by age. Thus, while a suspension of young spores (Io days from sowing of cultures) will readily germinate in pure water, those from a six-weeks old culture will no longer do so, though they are quite capable of germination in nutrient. Using spores of these two types the following results were obtained in comparative infection experiments with Cereus (considerable exosmosis) and Gloxinia (small exosmosis) :

Type of spore.
Young
Old
Young
Old"
"

$\quad$ Sown in.
Turnip extract
Water
Turnip extract
Water
Turnip extract
Water
Turnip extract
Water

Plant.
Cereus
",
Gloxinia
",
"

Time for infection
in all the drops.
IO-I I hours
II-I 2 "
$20-23 "$
$22-26 "$
$13-16 "$
$23-26 "$
$30-34 "$
none in 96 hours

The points brought out in the above table are as follows:

I. The time required for infection by the old spores is always greater than that in the case of the corresponding infection by young spores: in the present experiment about twice as long in each case.

2. In the case of Cereus, both types of spore attack the petal almost as readily when sown in water as when sown in turnip extract. In the case of Gloxinia, the spores sown in water attack distinctly more slowly than the corresponding sowings in turnip extract. This is especially the case when the old spores are sown in water. Here no attack takes place even after four days, thus showing that the spores have been unable to obtain an appreciable amount of nutrient from the plant. When, on the other hand, 
these old spores are sown in water on Cereus they attack readily enough, and for the reason that they obtain the nutrient necessary for their germination by passive exosmosis from the plant.

In a second experiment use was made of the fact that a certain concentration of carbon dioxide in the atmosphere inhibits the germination of Botrytis spores when sown in water, whereas the effect is relatively much less when the spores are sown in nutrient. Young spores of Botrytis were sown in water on petals of Rose and Cereus, in the one case in air, in the other in an atmosphere composed of 80 per cent. air and 20 per cent. carbon dioxide. In air attack readily took place in both cases, but in the carbon dioxide atmosphere only the Cereus was attacked. Even after three days the spores on Rose in the latter case were ungerminated. These results show that in Cereus the exosmosis of nutrient is sufficient to stimulate the germination of the spores in spite of the antagonistic effect of the carbon dioxide, whereas in the case of Rose the amount of exosmosis is insufficient for this purpose.

A third type of experiment was based on the fact that spores of Botrytis which germinate in pure water can be inhibited from doing so by sowing them sufficiently densely. This inhibiting effect is removed by the addition of a sufficiency of nutrient. Thus, while the effect of increasing the density of spore sowing is to diminish the amount of germination when the spores are sown in water, no such effect is obtained (at any rate within the same limits of spore concentration) when the spores are sown in nutrient.

In the case of Cereus petals which give high exosmosis figures, increase of spore concentration has no appreciable effect on the time of establishment of attack. In cases where the amount of exosmosis is much less, increase of concentration of spores leads to delay in the time of attack. Thus in an experiment with petals of Sweet-pea the folloning figures were obtained :

$\begin{array}{cccc}\begin{array}{c}\text { Relative Density } \\ \text { of spore sowing. }\end{array} & \begin{array}{c}\text { Number of } \\ \text { inoculations. }\end{array} & \begin{array}{c}\text { Number of } \\ \text { infections after } \\ 20 \text { hours. }\end{array} & \begin{array}{c}\text { Percentage of } \\ \text { infections. }\end{array} \\ \text { I/10 } & 57 & 49 & 86 \\ \text { I } & 53 & 30 & 57 \\ \text { IO } & 4 \mathrm{I} & 1 & 2 \cdot 5\end{array}$

These results are readily interpreted on the lines of the higher rate of exosmosis from Cereus and the smaller rate from Sweet-pea.

The effect of increased density of spore sowing was not so clearly marked as was anticipated. Though only one of the forty-one inoculations with the densest spore suspension had taken in twenty hours, nevertheless they all showed infection ultimately. Total inhibition was expected on the ground that when a drop of the spore suspension was added to a drop of water which had lain on the petal for several days no germination took place. A more striking illustration of this discrepancy was met with in 
experiments with Rose petals, where it was found that infection could be produced even when the spores were put on so thickly as to constitute a paste. Thus, while in the germination tests on glass it is readily possible to inhibit germination by increasing the concentration of spore sowing, the same is not possible in sowings on the petal itself.

On examining the dense suspension of spores which had begun to give infection of the petal it was seen that only a few spores had germinated, and these in the neighbourhood of the spots where attack was beginning. The apparent discrepancy is therefore probably explicable on the ground that in the case of the germination tests on glass the small quantity of nutrient is divided between a very large number of spores and produces no apparent effect as regards germination, whereas in the case of the infection drops on the petal itself the nutrient reaches the dirop unilaterally, and probably therefore is completely taken up by the spores lying in contact with the plant surface. The latter would thus be able to germinate and produce infection while the great bulk of the spores present remain ungerminated and ineffective.

\section{Exosmosis From Foliage LEAVES.}

The examination of foliage leaves in the present connexion has not been carried out in the same detail as in the case of floral structures. The reason for this lies in the fact that difficulty was experienced in obtaining a suitable plant and a suitable fungus for investigation.

All the petals examined show the common feature that they are readily attacked by spores of Botrytis when the latter are placed on the petal in suspension in pure water. In such a case therefore it is possible to examine the phenomenon of exosmosis in relation to attack. Up to the present, however, no plant has come under observation the leaves of which can be parasitized by Botrytis in this manner. Even with the leaves of Broad Bean, which have been so much used in investigations of parasitism of the Botrytis type, no satisfactory infection is shown when the fungal spores are placed on the leaf in pure water, though it takes place readily when extraneous nutrient is supplied. In these circumstances one has to be contented with examining the negative side of the problem, i. e. the relation between the particular exosmosis features presenting themselves and the absence of attack.

Measurements have been made of the exosmosis from leaves of Broad Bean, French Bean, and Tradescantia discolor. In all these cases very complete wetting of the leaves took place and high figures were obtained in the conductivity determinations. Thus in one experiment where a comparison was made between Beans grown in the open at ordinary temperature and others forced in a greenhouse at a higher temperature, the following figures for conductivity were obtained. (The leaves were all 
thoroughly rinsed in water beforehand to remove any foreign matter from the surface.)

Beans grown in open . . . . $\mathrm{I}_{3} 3 \cdot 4, \mathrm{I} 3 \cdot 8, \mathrm{I} 3 \cdot 8, \mathrm{I} 7 \cdot 6$

Beans forced in hothouse . . . $31 \cdot 9,35^{\circ} 6,44 \cdot 3,49 \cdot 2$

The exosmosis from the forced plants was considerably greater than that from those grown in the open, and in the case of both was greater than what is typically obtained from petals. Nevertheless these drops, when treated according to the method already described, had no appreciable effects in stimulating spore germination. They were found to be practically identical with distilled water in this respect.

The behaviour of the leaves in the present experiment as regards susceptibility to attack by Botrytis was found to be as follows :

Beans grown in the open-spores sown in nutrient-attack commencing in 22 hours.

Beans grown in the open-spores sown in water-no attack in seven days.

Beans grown in hot-house-spores sown in nutrient-attack commencing in 16 hours.

Beans grown in hot-house-spores sown in water-only doubtful attack in 7 days.

When the spores are supplied with extraneous nutrient, attack takes place readily in both cases, and it will be noticed that the time for the first signs of attack to appear is shorter for forced leaves than for leaves grown in the open. This feature is no doubt correlated with greater development of the cuticle in the latter case.

The slight amount of attack of the forced leaves by spores sown in water is of no interest, as it was observed that the leaves had markedly deteriorated during the long treatment. It can be truly stated that neither type of leaf shows any susceptibility to attack when the spores are sown in water. The non-susceptibility of these leaves is thus in complete agreement with the fact that the substances passing out have no nutrient value for Botrytis spores.

In the examination of some leaves an interesting result was met with, viz. that drops which had lain for some time on the surface of the leaf, and which were then found to possess a relatively high conductivity, actually produced less germination than did the distilled water controls. This result has been obtained in some cases with Bean leaves. The following table relating to an experiment with leaves of Tradescantia discolor illustrates this effect :

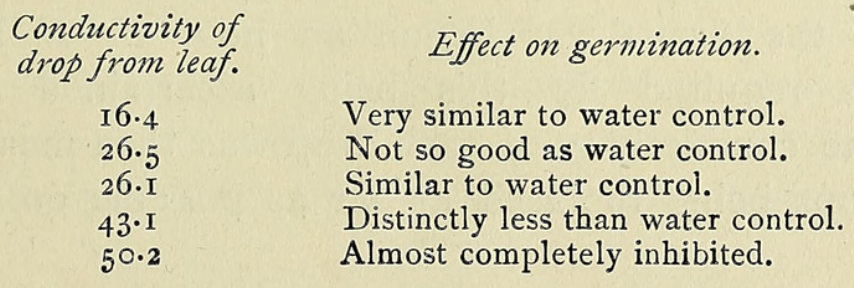

$\mathrm{K}$ 
Here, apart from slight irregularities, the amount of germination runs more or less inversely to the conductivity. The leaves had not been treated to a preliminary washing, so that the source of the conducting material cannot be definitely stated. It may have come mainly from the interior of the leaf or may have been present to a large extent as some kind of incrustation on the surface.

Though the present experiment relates to a case where there is no question of parasitic attack (it was found that only the most meagre attack took place even when the spores were sown in nutrient), nevertheless it is interesting as showing that spores when placed in distilled water on the surface of a leaf come under the influence of substances which are able to exercise an important effect on their germination.

It will be noticed incidentally that the correlation which was shown to exist between the figures for conductivity and for germinative capacity does not hold as from plant to plant. A drop of a given conductivity obtained from Bean leaves has a much smaller effect in stimulating germination than one of the same conductivity obtained from Cereus petals. Thus, apart from quantitative differences, there are qualitative differences between the substances diffusing out in the two cases.

\section{Effect of the Presence of Spores in the Drop on the} RATE OF ExOSMOSIS.

In an earlier paper of this series it was shown that the active principle obtained from Botrytis spores is unable to diffuse through the cuticle. Blackman and Welsford confirmed this result by showing that the first visible change in the cells of the host plant took place only after actual penetration of the cuticle had been effected. On the basis of these observations the conclusion was drawn that the fungus has no effect on the host until penetration of the cuticle has taken place. The presence or absence of spores in the drop would thus be immaterial as regards the rate of exosmosis into the drop so long as infection was in abeyance. This deduction has been strikingly confirmed by the use of the conductivity method.

The method of experimenting was as follows. Flowers of Sweet-pea proved to be most satisfactory for this purpose. They furnished very uniform conductivity figures and being symmetrical one side could be used as a control to the other. Drops of water were laid on the one side (e.g. the right wing and the right half of the standard), and drops of sporecontaining water on the other side (left wing and left half of standard). Examination of the drops was begun an hour or so before infection began, the time required for this being ascertained by preliminary experiment. The conductivity of each drop was then measured at hourly intervals, the drops being replaced as far as possible on the part of the 
petal from which they had been taken. Side by side with these readings the petals were closely examined for the first macroscopic appearance of infection, i.e. for the presence of small discoloured spots or, what was found to be a better test, for the presence of small translucent patches when the petals were viewed by transmitted light. In this way the progress of infection was studied side by side with the rate of exosmosis into the drops. The following table gives the results obtained in one particular experiment :

\begin{tabular}{|c|c|c|c|c|c|c|}
\hline & & Cond & ty at th & lowing & als fron & ing : \\
\hline & & 5 hrs. & $6 \mathrm{hrs}$. & $7 \mathrm{hrs}$. & $8 \mathrm{hrs}$. & $9 \mathrm{hrs}$. \\
\hline $\begin{array}{c}\text { Spore-free } \\
\text { drops. }\end{array}$ & $\begin{array}{l}\text { I. } \\
2 .\end{array}$ & $\begin{array}{l}2 \cdot 17 \\
2 \cdot 30\end{array}$ & $\begin{array}{l}3 \cdot 81 \\
4 \cdot 16\end{array}$ & $\begin{array}{l}5 \cdot 73 \\
5 \cdot 29\end{array}$ & $\begin{array}{l}6.64 \\
6.29\end{array}$ & $\begin{array}{l}7.99 \\
6.99\end{array}$ \\
\hline & 3. & $2 \cdot 3^{8}$ & $4.2 \mathrm{I}$ & $5 \cdot 5^{8}$ & 6.64 & $7 \cdot 54$ \\
\hline & 4. & $2 \cdot 44$ & $4 \cdot 16$ & $5 \cdot 29$ & 6.05 & 6.84 \\
\hline & 5. & $2 \cdot 48$ & $4 \cdot 21$ & $5 \cdot 39$ & $6 \cdot 26$ & 6.89 \\
\hline & 6. & $2 \cdot 48$ & $4 \cdot 3 \mathrm{I}$ & $5 \cdot 4 \mathrm{I}$ & $6 \cdot 3 \mathrm{I}$ & $7 \cdot 18$ \\
\hline & 7. & $2 \cdot 4^{8}$ & $4 \cdot 66$ & 6.29 & $6 \cdot 58$ & $7 \cdot 67$ \\
\hline & 8. & 2.55 & 3.87 & $5 \cdot 22$ & 6.03 & 6.89 \\
\hline & 9. & 2.82 & $4 \cdot 84$ & $6 \cdot 45$ & $7 \cdot 5^{\mathrm{I}}$ & 8.55 \\
\hline & Io. & $2 \cdot 82$ & $5 \cdot 04$ & 6.84 & $7 \cdot 34$ & S.O5 \\
\hline & I I. & $2 \cdot 89$ & $4 \cdot 58$ & $5 \cdot 92$ & $6.9^{2}$ & $7 \cdot 64$ \\
\hline & I 2. & 2.99 & $4 \cdot 93$ & $6 \cdot 5^{6}$ & $7 \cdot 61$ & 8.94 \\
\hline & I 3 . & 3.21 & 5.08 & $6 \cdot 2 \mathrm{I}$ & 7.21 & 8.02 \\
\hline & I 4 . & $3 \cdot 37$ & 4.60 & $5 \cdot 77$ & 6.86 & $7 \cdot 5^{8}$ \\
\hline Spore-con- & I. & $2 \cdot 18$ & $3 \cdot 6 \mathrm{I}$ & $4 \cdot 90$ & 6.25 & $8 \cdot 4^{8}$ \\
\hline taining drops. & 2. & $2 \cdot 3^{2}$ & 3.95 & $5 \cdot 20$ & $6 \cdot 39$ & $8 \cdot 35$ \\
\hline & 3. & $2 \cdot 36$ & $3 \cdot 95$ & $5 \cdot 18$ & $6 \cdot 4^{8}$ & $8 \cdot 3^{2}$ \\
\hline & 4. & $2 \cdot 50$ & $3 \cdot 64$ & $* 6.78$ & I9.35 & $4^{I} \cdot 4^{I}$ \\
\hline & 5. & $2 \cdot 69$ & $4 \cdot 45$ & 6.23 & ${ }^{*} 9 . \circ 3$ & 13.96 \\
\hline & 6. & 2.92 & $4 \cdot 45$ & $*_{5} \cdot 72$ & 6.64 & 8.08 \\
\hline & 7. & 3.06 & 4.73 & $* 6.3 \mathrm{I}$ & $9 \cdot 37$ & I 8.76 \\
\hline & 8. & 3.09 & $4 \cdot 64$ & $* 6 \cdot 34$ & $8 \cdot 45$ & I 2.57 \\
\hline & 9. & $3 \cdot 16$ & $4 \cdot 49$ & 5.80 & 6.86 & 8.18 \\
\hline & IO. & 3.28 & 4.82 & $6 \cdot 16$ & $7 \cdot 04$ & $7 \cdot 99$ \\
\hline & I I. & $3 \cdot 83$ & $5 \cdot 90$ & $* 8.45$ & I $3 \cdot 77$ & $23 \cdot 4^{2}$ \\
\hline & I 2. & $3 \cdot 89$ & $6 \cdot 34$ & *I I.IO & 19.54 & $3 \mathrm{I} \cdot 57$ \\
\hline & I 3. & 3.99 & 5.90 & ${ }^{*} 9.59$ & I $8 \cdot 76$ & $3^{1} \cdot 70$ \\
\hline & I 4. & 4.51 & $* 7 \cdot 89$ & I 7.66 & $33 \cdot 75$ & \\
\hline
\end{tabular}

At the end of five hours from sowing no attack was visible in any case on macroscopic examination. At this time the average conductivity of the fourteen drops which contained spores was $3.1 \mathrm{I}$, that of the controls 2.67 . The initial conductivity of the spore suspension was $I \cdot 3$, that of water 0.9 . Making this correction it is seen that the difference in rates of exosmosis in the two cases is negligible.

Throughout the whole series it is seen that the rate of increase in conductivity is very similar in the spore-containing drops to that in the controls until such time as infection was seen to have occurred. When this happened the conductivity of the spore-containing drops in general rapidly rose to high values, the surface of the petal in contact with the drop becoming in the meanwhile entirely discoloured through the coalescence 
of a large number of discoloured spots. In some cases the first attack might be very localized, only one spot appearing for a considerable time, in which case the rise in conductivity in the drop subsequent to attack took place more gradually (No. 6 of spore-containing drops in the preceding table).

By the time infection can be detected macroscopically it has already progressed to some extent; the first stages of attack can only be demonstrated microscopically. This is readily done by taking a thin surface section of the petal and viewing it from above in the field of the microscope. Penetration, when it has taken place, is shown by the different appearance of the portion of the hypha within the tissue, the margins being more hazy than those of the hyphae external to the tissue, and also by the necessity of focusing at a lower level. Further, the internal portion of an invading hypha appears to follow a direction entirely independent of the original (external) hypha, and so the point of penetration is almost invariably marked by a sharp bend in the hypha when the latter is looked at from a direction at right angles to the leaf surface.

In experiments of the above type it was repeatedly proved that infection had already taken place in cases where there was no visible macroscopic discoloration and where there was no evidence whatever of any tendency towards an increased rate of exosmosis into the sporecontaining drops as compared with the controls. Infection could thus always be demonstrated by ocular means before any effect on exosmosis, due to the presence of the fungus, appeared $;^{1}$ in other words, the rate of exosmosis into the spore-containing drops is the same as into the spore-free drops until such time as penetration has taken place in the case of the former. According to the view of 'action in advance of penetration' put forward by de Bary, the rapid exosmosis of nutrient substances from the host cells takes place antecedent to penetration, and is in fact responsible for the germination of the fungal spores and for their attack. It is clearly shown, however, by the preceding data that penetration has already taken place before the rapid exosmosis due to killing of the host cells has begun. In fact, it is only some time after infection that any divergence in the rates of exosmosis between the spore-free and the spore-containing drops takes place. This lag would be explained on the basis of the time required for the invading hyphae to kill the adjacent cells of the host and for the soluble contents of the killed cells to diffuse out into the infection drop.

These results are thus in complete agreement with the views put forward in the earlier papers of this series and in opposition to the view of de Bary on this subject.

1 Indeed, in one very fortunate case, penetration of the cuticle was seen to have taken place while the host cell immediately underlying the point of penetration had not yet lost its colour and was still plasmolysable. 


\section{Discussion of Results.}

It would be premature, with the data at present available, to try to estimate the significance of the foregoing results in relation to the physiological processes of infection. The present paper deals mainly with floral organs, and thus touches only a small and unimportant part of the field of parasitism. As has been already stated, the difficulty met with in the treatment of foliage leaves lay in the fact that no satisfactory parasitism of the leaves investigated could be brought about by Botrytis. Thus the examination of foliage leaves according to the method of the present paper could be carried out only in its negative aspect. With a view to the further development of this problem an investigation of some fungus more suitable for this purpose than Botrytis is projected.

In all the cases examined it has been found that drops of water when laid on the surface of plant structures show an increase of conductivity, which increase has been found in a number of instances to be accompanied by an increased capacity for stimulating germination. The increase of conductivity, due to leaching of electrolytes from the plant, is in agreement with a large body of recent work dealing with the permeability of the living cell-membrane to electrolytes (and other simple solutes) and requires no further emphasis here. From the pathological point of view the essential point brought out is that water drops when laid on plant structures are altered in respect of their capacity to stimulate spore germination. Drops so treated show in some cases a very marked increase in this respect; in other cases the effect obtained is much less; and finally cases were met with in which the treatment actually reduced the amount of germination as compared with that taking place in the water controls. As it has been proved in earlier papers that the fungal spores exert no influence on the host previous to penetration of the cuticle, it is obvious that the preceding results which were obtained for drops of water laid on the plant are directly applicable to the infection drops themselves. The amount and quality of the substances diffusing into the infection drop must obviously exert an important influence on the behaviour of spores. Where the substances diffusing out from the plant have a marked stimulating effect on germination, the fungal spores when sown in water will germinate as in nutrient and will therefore be able to attack the plant with the vigour induced by good nutrition. Where the substances diffusing from the plant are such that they exert no appreciable influence one way or the other on the germination of the fungal spores, the course of affairs will be largely dependent on the inherent vigour of the spores. If these are young, a certain amount of germination will take place and attack may in some cases follow; if they are old (or in other ways attenuated), 


\section{8 Brown.-Studies in the Physiology of Parasitism. VIII.}

germination will not take place and no attack will be possible. Lastly, where the substances diffusing from the plant are such as to inhibit the spore germination, it is obvious that no attack can take place in the circumstances.

It is well known that in some cases immunity is in no way related to considerations such as those outlined above. Thus in some of the Rusts it has been shown that both immune and susceptible varieties of the host are actually penetrated by the fungus. The differential effect appears only after penetration has taken place, inasmuch as further growth of the fungus is inhibited in the case of the immune variety, whereas it continues in the other. Here, therefore, the immunity or susceptibility of the host is not due to conditions prevailing in the infection drop, but to different and more complex relationships between host and parasite which come into play only after penetration has taken place. Nevertheless, there are cases where attack is determined by the conditions prevailing in the infection drop. The parasitism of the Bean leaf by Botrytis is a case in point. Here the incidence of attack is dependent on whether sufficient nutrient is present in the infection drop to enable the fungus to germinate and penetrate the cuticular layer. If nutrient is present, attack takes place with readiness; if no nutrient is present, the attack fails. It is to parasitism of this type that the present results apply, and in which the methods of investigation outlined above may prove of value in determining just why attack fails in some cases and why it succeeds in others.

\section{SUMmary.}

I. Drops of distilled water which have lain on the surface of leaves and petals of a number of plants show increased conductivity as compared with the original distilled water or with water which has lain for an equal time on glass slides.

2. This increase in conductivity is accompanied in many cases (e.g. floral leaves) by a greatly increased capacity of the drops to bring about germination of Botrytis spores as compared with that of the original water. In some plants drops so treated, though showing a comparatively high degree of conductivity, have no greater effect on germination than drops of pure water. In some cases, even, the treated drops actually produce total inhibition of the fungal spores.

3. In the case where increased germination effects are observed the amount of germination runs parallel with the conductivity.

4. The ease or difficulty with which wetting of the plant surface takes place is an important factor in determining the magnitude of the effects produced. 
5. Indirect proof of the exosmosis of nutrient can be obtained by a study of the incubation times of infection in different cases.

6. The rate of exosmosis into drops containing Botrytis spores is identical with that into spore-free drops, up to and for some time after penetration by Botrytis has taken place. The rate of exosmosis then increases with great rapidity in the case of the infection drops.

The writer wishes to express his indebtedness to Mr. S. G. Crater, of Rocky Mount, North Carolina, for his help in the experiments dealing with the effect of age on the permeability of petals, as described on p. 104, and also for repeating and verifying a number of other results. 


\section{$2 \mathrm{BHL}$ Biodiversity Heritage Library}

Brown, William. 1922. "Studies in the physiology of parasitism. VII. On the exosmosis of nutrient substances from the host tissue into the infection drop." Annals of botany 36, 101-119.

https://doi.org/10.1093/oxfordjournals.aob.a089782.

View This Item Online: https://www.biodiversitylibrary.org/item/234428

DOI: https://doi.org/10.1093/oxfordjournals.aob.a089782

Permalink: https://www.biodiversitylibrary.org/partpdf/319030

\section{Holding Institution}

Smithsonian Libraries

\section{Sponsored by}

Biodiversity Heritage Library

\section{Copyright \& Reuse}

Copyright Status: Not in copyright. The BHL knows of no copyright restrictions on this item.

This document was created from content at the Biodiversity Heritage Library, the world's largest open access digital library for biodiversity literature and archives. Visit BHL at https://www.biodiversitylibrary.org. 